\title{
EHMTI-0091. Physiotherapy interventions for headaches: a systematic review and meta-analysis
}

\author{
K Luedtke*, A May \\ From 4th European Headache and Migraine Trust International Congress: EHMTIC 2014 \\ Copenhagen, Denmark. 18-21 September 2014
}

\section{Background}

Headaches are a common condition with high socioeconomic impact.

Guidelines recommend medication but rarely include physiotherapy. However, patients report pain relief from exercises, mobilisation and massage. A systematic review with a literature search up to $11 / 2002$ concluded that physical treatments may be effective but that further research might change this result.

\section{Aim}

To evaluate the current level of evidence for physiotherapy on headache symptoms.

\section{Methods}

Search strategy with pre-defined key terms conducted in MEDLINE, CENTRAL, PeDRO, reference lists of retrieved articles, and journal contents. Controlled trials, employing physiotherapy interventions for the reduction of headaches published in any language between 11/2002 and 04/2014 were included. Studies using chiropractic, osteopathic or acupuncture techniques were excluded. Quality was evaluated using the Cochrane risk of bias tool.

\section{Results}

Twenty-two trials were eligible, 19 reported outcome measures allowing combination in a meta-analysis. Physiotherapy included mobilisation, exercises, relaxation, massage, and physiotherapy as part of a multidisciplinary intervention. Headache types included migraine, TTH, CGH and mixed/undefined headache populations. A meta-analysis for pain reduction found a pooled effect size of -9.97 on a $0-100$ VAS $(95 \%$ CI $-18.55 ;-1.38)$. Frequency was reduced by -2.78 days/months $(95 \% \mathrm{CI}-4.69 ;-0.87)$, duration by

Institute of Systems Neurosciences, University Medical Center HamburgEppendorf, Hamburg, Germany

(c) 2014 Luedtke and May; licensee Springer. This is an Open Access article distributed under the terms of the Creative Commons Attribution License (http://creativecommons.org/licenses/by/2.0), which permits unrestricted use, distribution, and reproduction in any medium, provided the original work is properly cited.
-7.52 hours/attack (95\%CI -10.49; -4.55). Sub-analyses indicated effectiveness for the reduction of pain intensity, frequency and duration of migraine, TTH, CGH and mixed/undefined headache populations.

\section{Conclusions}

There is a high level of evidence that physiotherapy is effective for headache reduction. Physiotherapy is low-cost has no side-effects and potentially reduces medication use and work absenteeism.

No conflict of interest.

Published: 18 September 2014

doi:10.1186/1129-2377-15-S1-D38

Cite this article as: Luedtke and May: EHMTI-0091. Physiotherapy

interventions for headaches: a systematic review and meta-analysis. The Journal of Headache and Pain 2014 15(Suppl 1):D38.

Submit your manuscript to a SpringerOpen ${ }^{\odot}$ journal and benefit from:

- Convenient online submission

- Rigorous peer review

- Immediate publication on acceptance

- Open access: articles freely available online

- High visibility within the field

- Retaining the copyright to your article

Submit your next manuscript at $\gg$ springeropen.com 